\title{
Comparative genome analysis of Wolbachia strain wAu
}

\author{
Elizabeth R Sutton ${ }^{1}$, Simon R Harris ${ }^{2}$, Julian Parkhill ${ }^{2}$ and Steven P Sinkins ${ }^{1,3^{*}}$
}

\begin{abstract}
Background: Wolbachia intracellular bacteria can manipulate the reproduction of their arthropod hosts, including inducing sterility between populations known as cytoplasmic incompatibility (Cl). Certain strains have been identified that are unable to induce or rescue $\mathrm{Cl}$, including wAu from Drosophila. Genome sequencing and comparison with Cl-inducing related strain wMel was undertaken in order to better understand the molecular basis of the phenotype.

Results: Although the genomes were broadly similar, several rearrangements were identified, particularly in the prophage regions. Many orthologous genes contained single nucleotide polymorphisms (SNPs) between the two strains, but a subset containing major differences that would likely cause inactivation in wAu were identified, including the absence of the wMel ortholog of a gene recently identified as a $\mathrm{Cl}$ candidate in a proteomic study. The comparative analyses also focused on a family of transcriptional regulator genes implicated in $\mathrm{Cl}$ in previous work, and revealed numerous differences between the strains, including those that would have major effects on predicted function.
\end{abstract}

Conclusions: The study provides support for existing candidates and novel genes that may be involved in $\mathrm{Cl}$, and provides a basis for further functional studies to examine the molecular basis of the phenotype.

Keywords: Wolbachia, wAu, wMel, Genome, Cytoplasmic incompatibility, Prophage, Transcriptional regulator, PacBio sequencing

\section{Background}

Wolbachia pipientis is a maternally inherited intracellular bacterium that infects a very large number of arthropod and nematode species [1] and can induce a variety of reproductive manipulations in arthropods to confer a selective advantage on infected females, thus promoting population invasion [2]. The most common manipulation is known as cytoplasmic incompatibility (CI) [2]. In the simplest form of unidirectional CI, uninfected females produce inviable offspring when mated with Wolbachiainfected males, while Wolbachia-infected females produce viable offspring when mated with both infected and uninfected males. Bidirectional CI can also occur, in which Wolbachia-infected females are incompatible with males infected with a different Wolbachia strain. At present little is known about the molecular mechanisms of $\mathrm{CI}$, and this represents a critical roadblock in our understanding of

\footnotetext{
* Correspondence: s.sinkins@lancaster.ac.uk

'Department of Zoology and Peter Medawar Building for Pathogen Research, Nuffield Department of Medicine, University of Oxford, Oxford, UK ${ }^{3}$ Biomedical and Life Sciences, Lancaster University, Lancaster, UK Full list of author information is available at the end of the article
}

Wolbachia biology. Identification of CI genes would also be beneficial for disease control applications using Wolbachia. Some Wolbachia strains have been found to block or reduce transmission of human viruses [3-7] and parasites such as filarial nematodes and Plasmodium [3,8-11]; use of inhibitory Wolbachia for population replacement has shown considerable promise in field trials [12].

One approach to identifying genes involved in $\mathrm{CI}$ is genomic analysis of Wolbachia, comparing closely related incompatible strains with each other, or comparing CI-inducing strains with related strains that do not induce CI. In D. simulans the Wolbachia variant wAu expresses neither sperm modification in males, nor rescue of CI in females [13-17]; in other words $w \mathrm{Au}$ is 'mod- resc-', while CI-inducing strains are designated $\bmod +\operatorname{resc}+[2]$. The $w \mathrm{Au}$ strain has, however, been shown to provide its Drosophila host with a degree of protection against the effects of pathogenic viruses [18]. The $w$ Mel strain, from D. melanogaster, is most closely related to $w \mathrm{Au}$ and does induce CI; thus genes differing between these strains are candidates for involvement in 
CI [19]. The genome sequence of wMel has already been reported [20], so here we undertook $w \mathrm{Au}$ genome sequencing in order to enable a comparative analysis.

Although the genomes of several Wolbachia strains have been published [20-26], acquisition of sequence data has been limited by the difficulty in obtaining a sufficient quantity and purity of Wolbachia genomic DNA (gDNA). Wolbachia are obligate endosymbionts that cannot be cultured outside of their hosts, and are often present in relatively low abundance. Obtaining enough gDNA has thus required time-consuming amplification and purification protocols to minimize contamination with host gDNA. In addition, assembly has been complicated by numerous repeated sequences. Here we utilised the Pacific Biosciences (PacBio) RS II platform for sequencing; the long reads generated by this technology facilitate assembly through genomic repeats.

Previous comparative analysis of the genomes of mutual incompatibility-generating Wolbachia wPip sub-strains infecting Culex pipiens mosquitoes [21,22] revealed highly similar genomes with a small number of whole gene differences. Most notably this included a transcriptional regulator gene designated $w \operatorname{tr} M$ identified in $w$ Pip from Cx. molestus ( $w$ PipMol) but absent in $w$ Pip from $C x$. quinquefasciatus Pel and JHB ( $w$ PipPel and $w$ PipJHB), which are bidirectionally incompatible with $C x$. molestus [22]. Transfection of $C x$. quinquefasciatus females with wtrM resulted in significant upregulation of CPIJ005623, a host gene implicated in CI based on knockdown studies [22]. Eight paralogous putative transcriptional regulator genes are present in wMel (WD0254, WD0255, WD0296, WD0508, WD0622, WD0623 and WD0626 and WD0627). A specific comparison of these transcriptional regulator genes in $w \mathrm{Mel}$ and their homologs in $w \mathrm{Au}$ was therefore conducted to further investigate the hypothesis that disruptions to these genes could be responsible for the different CI phenotypes of these strains.

\section{Results and discussion}

\section{Genomic DNA purity assessment}

Approximate calculations based on quantitative PCR (qPCR) $\mathrm{C}(\mathrm{t})$ values for $w \mathrm{Au}$ and host genes were performed to estimate the degree of contamination with host gDNA in $w A$ gDNA samples extracted from cultured cells and whole adult flies. The estimated purity of $w \mathrm{Au}$ gDNA was $\sim 60 \%$ for the extract from cultured cells, and > $90 \%$ for the extract from whole adult flies. The latter is comparable to the figure of up to $97 \%$ reported previously [27] using the same extraction method. There is no previous data on Wolbachia gDNA extraction from cultured cells. One explanation for the lower purity could be that Wolbachia densities may be lower within cultured cells than in vivo.

\section{Genome sequencing and assembly}

$w \mathrm{Au}$ genome sequencing was initially performed using the Illumina platform on gDNA extracted from whole adult files. However, the resulting assembly was fragmented in the regions of most interest, with scaffold positions uncertain. A second round of sequencing was therefore performed using the PacBio RS II system to obtain longer reads in an attempt to improve the assembly, using gDNA extracted from cultured cells rather whole adult files. The Illumina data was used to correct errors in the PacBio reads, which assembled into a single contig.

The achievement of a single contig assembly shows that PacBio represents an extremely useful new sequencing platform for rapid generation of finished bacterial genome assemblies. Furthermore, the generation of this single contig from a very small amount of DNA (approximately $2 \mathrm{ng}$ ), containing a substantial amount of host DNA contamination ( $40 \%)$, suggests that PacBio is well suited to use in cases where it is hard to obtain a large amount of gDNA, including obligate endosymbionts, like Wolbachia, that cannot be cultured outside of host cells. The sequence generated was largely consistent with data produced using the Illumina platform, with only one single nucleotide polymorphism (SNP) between the two datasets. There were 88 indels relative to Illumina data; these were mostly single nucleotide insertions in the PacBio sequence, and were located in homopolymeric tracts, regions that are known to be prone to insertion errors in PacBio sequencing $[28,29]$. These were corrected after mapping the Illumina reads to the PacBio assembly. Combining the PacBio reads with the shorter but more accurate Illumina reads was found to be a very useful approach, consistent with other findings [30,31].

The use of cultured insect cell lines to obtain gDNA for genome sequencing represents a methodological departure from previous studies. All previous Wolbachia genomes have been sequenced using gDNA extracted directly from their native hosts. It is a time-consuming and often laborious process to rear sufficient numbers of the host insects for Wolbachia gDNA extraction, particularly for species with demanding rearing requirements. Transinfection of cells with Wolbachia is fairly easy to achieve, and amplification of cells to a suitable number is easier, quicker, and requires less space than whole organisms; this study used 24 flasks of cells, which were generated from a single flask in a few weeks. Concerns that the sequence of the $w \mathrm{Au}$ from cultured cells might have accumulated differences compared to the $w$ Au genome found in flies, due to a relaxation in cell lines of the selective pressures that apply in its native host, were alleviated by the observation of only one SNP between the sequence obtained using $w \mathrm{Au}$ from cultured cells and that using $w \mathrm{Au}$ from its native host. It is possible that after a longer period of time more differences from Wolbachia in vivo 
would accumulate, so use of recently generated Wolbachiainfected cell lines, as employed here, is advisable.

\section{wAu genome features}

The $w \mathrm{Au}$ genome is a single circular chromosome of $1,268,461 \mathrm{bp}$. It has 1266 predicted genes, corresponding to a coding content of $84 \%$. The major features of the genome, along with those of the $w \mathrm{Mel}$ genome, are shown in Table 1. Overall, the $w \mathrm{Au}$ and $w \mathrm{Mel}$ genomes are similar, but with a significant amount of rearrangement (Figure 1).

Like $w \mathrm{Mel}$, there is a large amount of DNA corresponding to mobile genetic elements in the wAu genome, including numerous insertion sequence (IS) elements. For example, 27 putative IS5 elements were identified, although most are likely to be inactive due to mutations or frameshifts. Some elements appear to have been active since the divergence of $w \mathrm{Mel}$ and $w \mathrm{Au}$, as their locations in the genome differ between the two strains. In some cases their movement has resulted in disruption of genes in one strain. In many cases where there are structural differences between the genomes of the strains, it seems that mobile elements have provided a mechanism for the rearrangement.

\section{Comparison of prophage regions}

There are three prophage regions in the $w \mathrm{Au}$ genome, as for $w \mathrm{Mel}$, although the location and structure of these regions differs between the two strains (Figures 2, 3, 4 and 5). The prophage region designated WO-A (Figure 2) in wMel (spanning WD0259 - WD0294) is inverted in $w \mathrm{Au}$ relative to $w \mathrm{Mel}$, and is further from the origin of replication (spanning WPWAU0631 - WPWAU0666). Several genes in this region differ in one strain relative to the other beyond SNPs (Figure 2). Four genes are disrupted in $w \mathrm{Au}$ relative to $w \mathrm{Mel}$, due to truncation (a shortened gene sequence due to partial deletion or genome rearrangement), frameshift, nonsense mutation, or start codon mutation, two are disrupted in $w \mathrm{Mel}$ relative to $w \mathrm{Au}$, and two contain small in frame indels.

The region designated WO-B (Figure 3) in $w \mathrm{Mel}$ (spanning WD0582 - WD0644) is closer to the origin

Table 1 General features of wAu and wMel genomes

\begin{tabular}{lll}
\hline & wAu & wMel \\
\hline Genome size (bp) & $1,268,461$ & $1,267,782$ \\
G + C content (\%) & 35.22 & 35.23 \\
Predicted CDSs & 1266 & 1195 \\
Coding density (\%) & 83.9 & 80.2 \\
Average gene size (bp) & 840 & 850 \\
Transfer RNAs & 34 & 34 \\
Ribosomal RNAs & 1 of each & 1 of each \\
Prophage regions & 3 & 3 \\
\hline
\end{tabular}

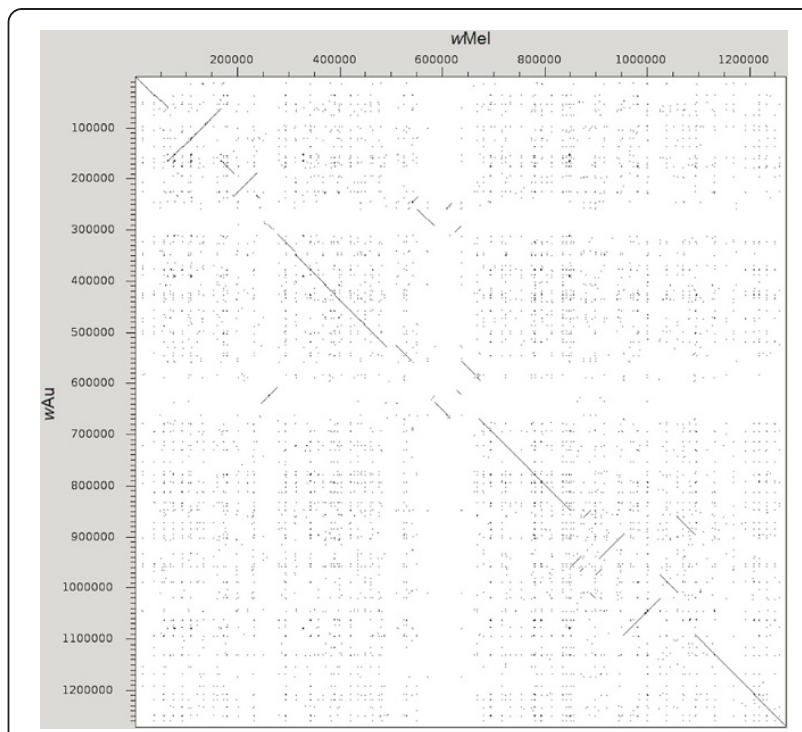

Figure 1 Similarity between $w A u$ and $w$ Mel genomes. A dot plot illustrating the similarity between wAu and wMel genomes. Axes show position in the genome (bp). Lines indicate regions of similarity. Lines on the diagonal from top left to bottom right indicate regions with the same location and arrangement in both genomes. Lines in the same orientation as this diagonal but located elsewhere indicate regions that are translocated in one genome relative to the other. Lines at right angles to the diagonal indicate regions that are inverted in one genome relative to the other. Parallel lines indicate repeated or similar regions.

of replication in $w \mathrm{Au}$ (spanning WPWAU0282 WPWAU0318). This region contains two segments, one closely related to P2 phage and the other to lambdoid phage [20]. In $w \mathrm{Au}$ the P2-like segment is inverted relative to its orientation in $w$ Mel. In addition, in $w \mathrm{Mel}$ there are intervening genes between the lambdoid-like block and P2-like block, whereas in $w \mathrm{Au}$ the two blocks are contiguous. These differences mean that unlike $w \mathrm{Mel} \mathrm{WO}-\mathrm{B}$, the gene order of $w \mathrm{Au}$ WO-B is highly conserved with that of WO phage in $w$ Kue [32], from which WO-A and WO-B were named [20]. As in WO-A, a high proportion of the genes in WO-B are disrupted in one of the two strains. Five genes are disrupted in $w \mathrm{Au}$ relative to $w \mathrm{Mel}$, due to truncation or frameshift; another five are disrupted in wMel relative to $w \mathrm{Au}$, due to frameshift, IS element insertion or start codon mutation. Several of the genes between the lambdoid-like and P2-like blocks in wMel, which include three of the transcriptional regulator genes discussed below, also differ significantly between $w \mathrm{Mel}$ and $w \mathrm{Au}$ (Figure 4). In addition to a higher than average frequency of SNPs between the two strains, five genes are disrupted in $w \mathrm{Au}$ relative to $w \mathrm{Mel}$, due to truncation, frameshift or nonsense mutation, while two are disrupted in $w \mathrm{Mel}$ relative to $w \mathrm{Au}$. Two genes 


\section{WO-A}

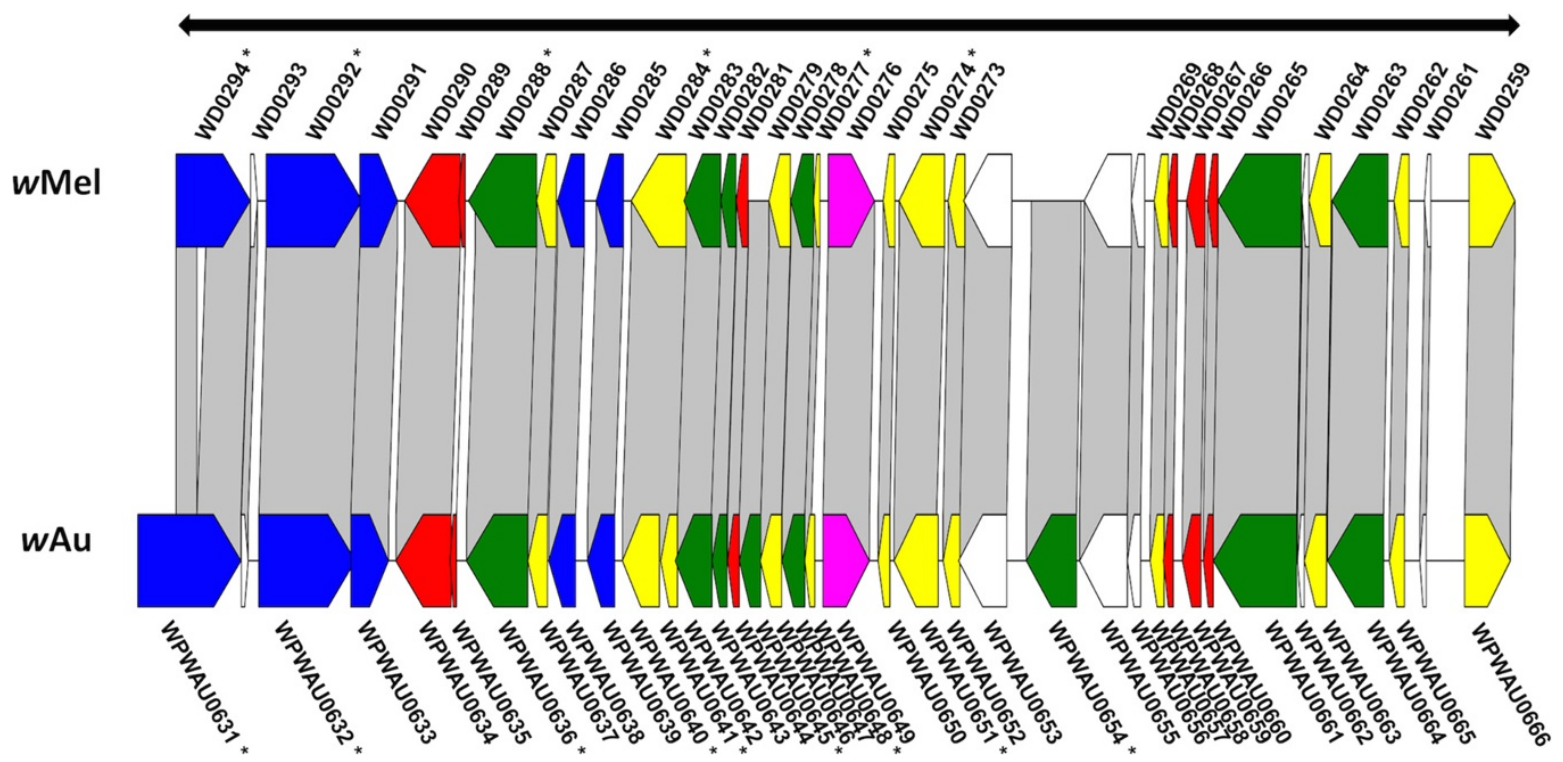

Figure 2 Comparison of WO-A in wAu and wMel. Alignment of the WO-A prophage region between wAu and wMel. Matching sequences corresponding to predicted CDSs, identified using ACT and Geneious alignments, are connected by grey blocks. Genes whose sequences differ between strains such that a CDS is not predicted in one strain are not represented in the strain lacking the predicted CDS, but their corresponding sequences are still connected to the CDSs in the other strain by grey blocks. The double-headed black arrow indicate regions that have been drawn inverted relative to their orientation in the genome, for clarity of alignment visualisation. Asterisks indicate genes with differences other than SNPs between wAu and wMel. Internal indels less than $20 \mathrm{bp}$ in size are not shown. Predicted CDSs are colour coded as follows: green, phage structural or replication genes; yellow, conserved hypotheticals; red, hypotheticals; blue, ankyrin repeat genes; magenta, transposases or reverse transcriptases. White arrows indicate sequences that are not annotated in one of the two strains and are probable pseudogenes or mis-annotations. Predicted CDSs that result from interruptions, frameshifts or nonsense mutations, which are combined into a single CDS in the other strain, are coloured the same as the CDS from which they are derived, even though they may also be pseudogenes.

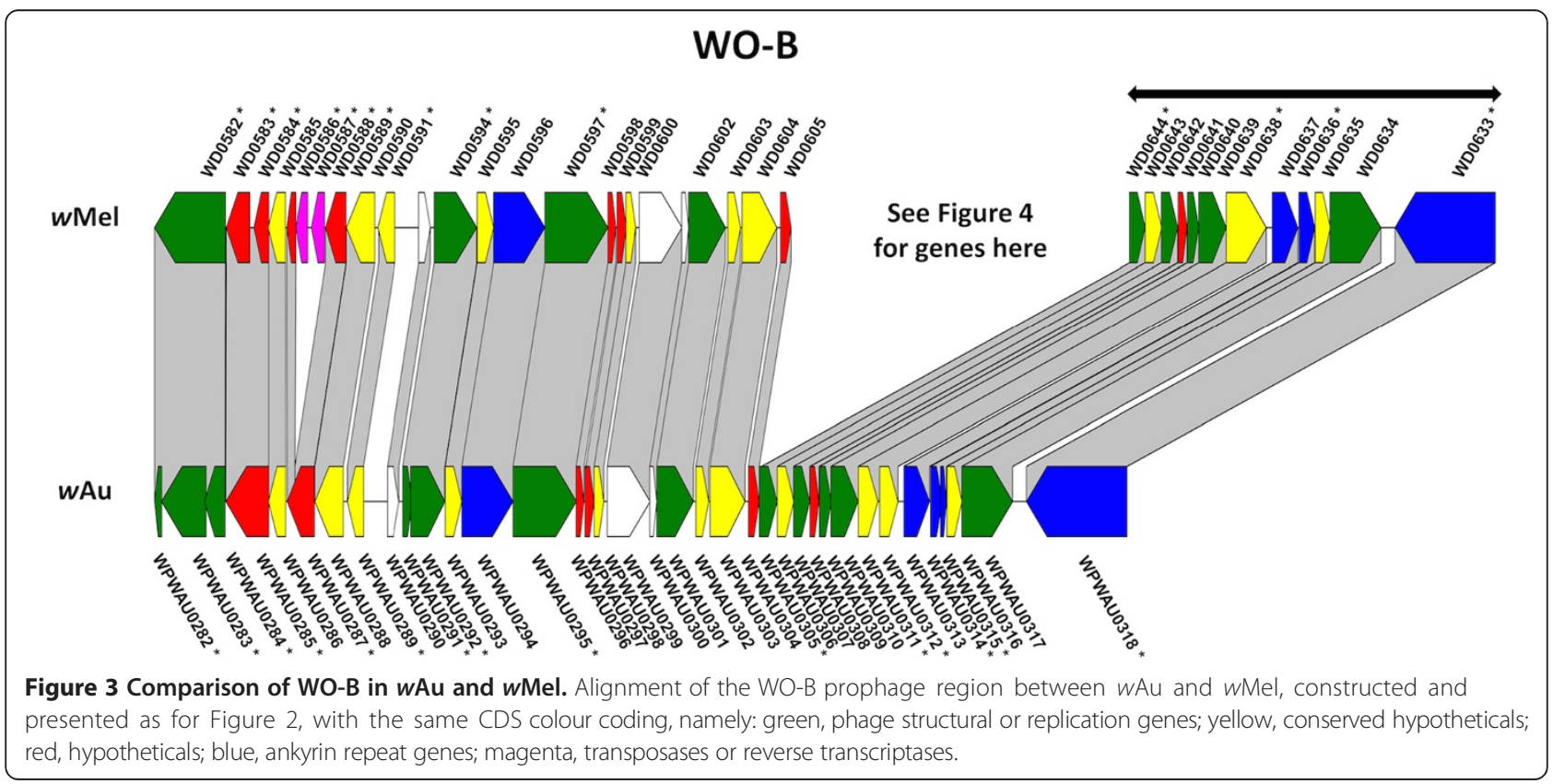




\section{Genes inserted within WO-B}

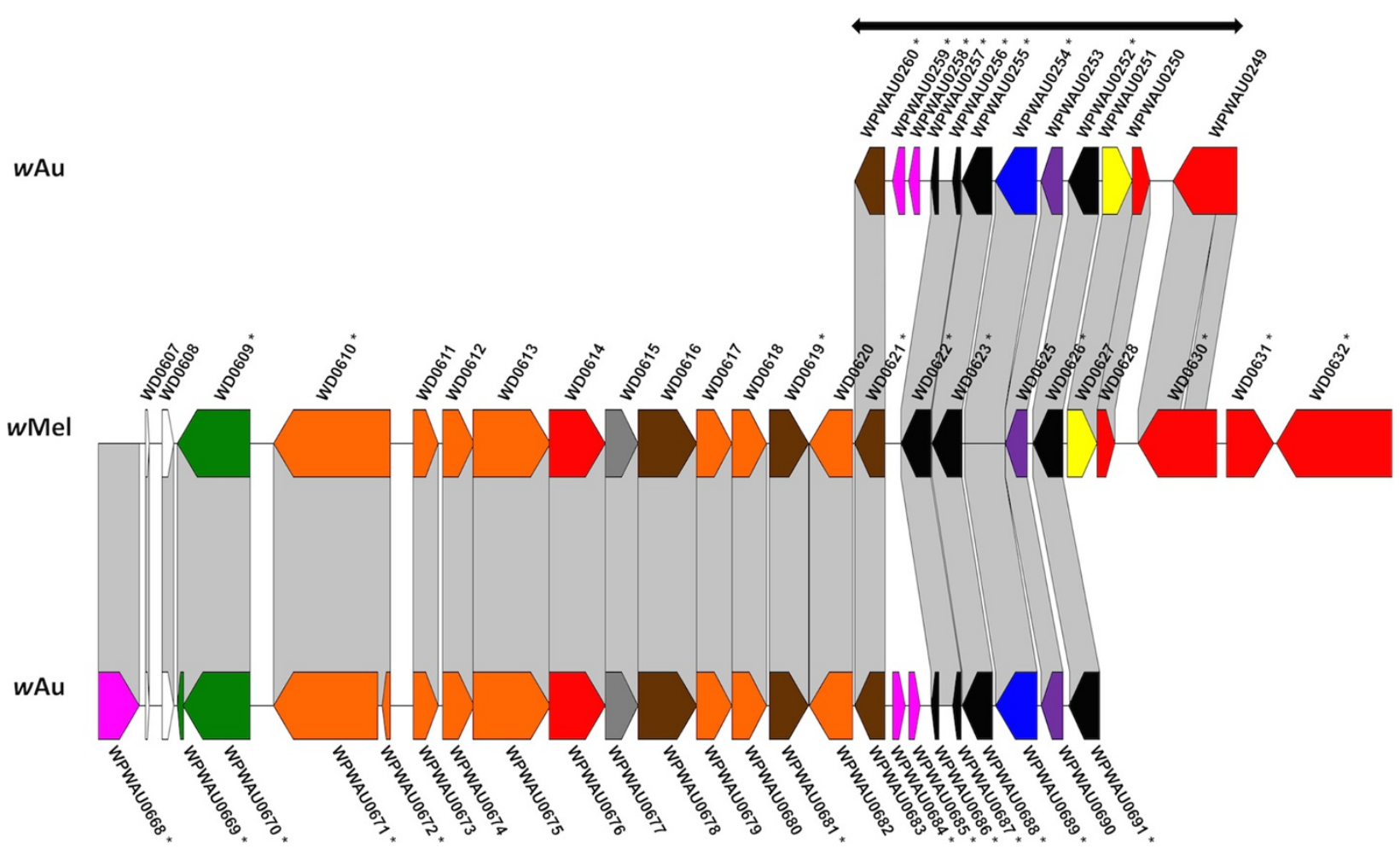

Figure 4 Comparison of genes inserted within wMel WO-B in wAu and wMel. Alignment of genes inserted within wMel WO-B between wAu and wMel, constructed and presented as for Figure 2, with the CDS colour coding: green, phage structural or replication genes; yellow, conserved hypotheticals; red, hypotheticals; blue, ankyrin repeat genes; magenta, transposases or reverse transcriptases; orange, enzyme genes; brown, membrane protein genes; purple, radC; black, transcriptional regulator genes; grey, others.

contain small indels, and two more (WD0631 and WD0632) are absent in $w \mathrm{Au}$, discussed further below.

The third prophage region, a small pyocin-like element comprising WD0565 - WD0574 in wMel (Figure 5), is closer to the origin of replication in $w A$ u (comprising WPWAU0263 - WPWAU0275). One gene is disrupted in $w \mathrm{Au}$ relative to $w \mathrm{Mel}$, by a nonsense mutation, and four genes are disrupted in $w \mathrm{Mel}$ relative to $w \mathrm{Au}$, by frameshift, nonsense mutation or truncation. In addition, there is an insertion after the first gene in $w$ Au relative to $w \mathrm{Mel}$, in which two additional genes are annotated. Overall the level of difference between $w \mathrm{Mel}$ and $w \mathrm{Au}$ in these three prophage regions is much higher than elsewhere in the genome.

\section{Genes potentially inactive in wAu}

Various other $w \mathrm{Mel}$ genes were also identified with large differences potentially causing inactivation in $w \mathrm{Au}$, or which are absent from $w A$ u entirely, as listed in Table 2. It is likely that $\mathrm{CI}$ is a complex process involving many genes, with the host genetic background also playing a role [33-35]. Any genes with differences between CI and non$\mathrm{CI}$ inducing strains are possible candidates for involvement in the process, but it seems reasonable to focus more attention on genes that are entirely absent or potentially inactivated. As has previously been reported [19], a region corresponding to genes WD0506 to WD0518 is absent in wAu; no other indel of comparable size to the WD0506 to WD0518 segment was found to be absent in the wAu genome. However, of note was the absence in $w \mathrm{Au}$ of two genes, WD0631 and WD0632, that have recently been identified as CI candidates due to the detection in $C x$. pipiens spermathecae of a protein corresponding to the WD0631 ortholog in the wPip strain [36]; the WD0631 and WD0632 orthologs are transcribed as an operon [36]. Various other genes are potentially inactivated in $w \mathrm{Au}$ relative to $w \mathrm{Mel}$, by truncation, frameshift, mobile element insertion, nonsense mutation or start codon mutation, as shown in Table 2. Whether and how these differences contribute to $\mathrm{CI}$ is worthy of further investigation.

\section{Comparison of transcriptional regulator genes}

Following a prior comparative genomic study of substrains of $w$ Pip Wolbachia from Cx. pipiens mosquitoes [22], which implicated a transcriptional regular gene designated $w \operatorname{trM}$ in $\mathrm{CI}$, a comparison of the family of transcriptional 


\section{Pyocin-like element}

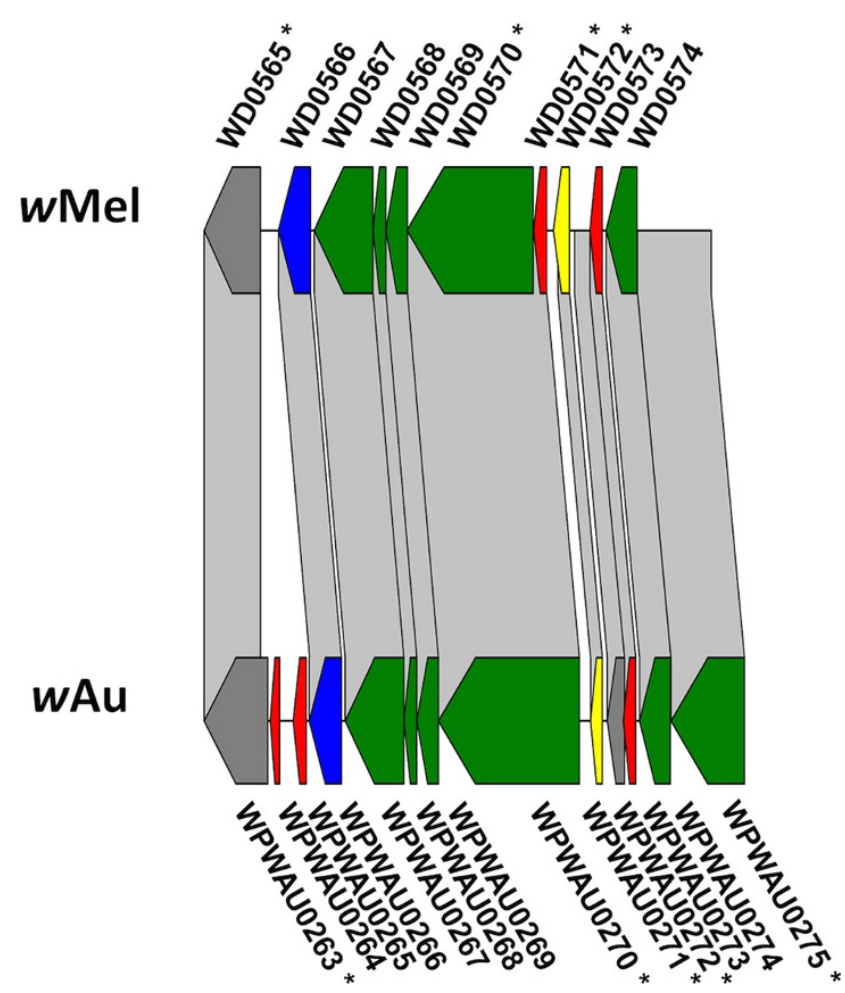

Figure 5 Comparison of pyocin-like element in wAu and wMel. Alignment of the pyocin-like prophage region between wAu and wMel, constructed and presented as for Figure 2, with the CDS colour coding: green, phage structural or replication genes; yellow, conserved hypotheticals; red, hypotheticals; blue, ankyrin repeat genes, grey, others.

regulator genes between $w \mathrm{Au}$ and $w \mathrm{Mel}$ constituted a focus of this study. These transcriptional regulator genes were found to differ in both organisation in the genome and sequence. Figure 6 illustrates the homology between $w$ Au and $w$ Mel transcriptional regulator genes; also shown is a comparison between $w \mathrm{Mel}$ and $w \mathrm{Ri}$, a Cl-inducing strain found in $D$. simulans. Figure 7 illustrates the differences between proteins that would be produced from the $w$ Mel transcriptional regulator genes and their corresponding sequences in $w \mathrm{Au}$. Of particular note is that the ortholog of WD0622 is highly disrupted by a frameshift in $w A u$. The two identical sequences corresponding to WD0622 (WPWAU0256 and WPWAU0687) have a $1 \mathrm{bp}$ insertion in $w A$ u relative to $w \mathrm{Mel}$, after bp 212, which causes a frameshift that would lead to premature termination of translation after 85 amino acids. Genes corresponding to the last 82 amino acids of WD0622 (WPWAU0257 and WPWAU0686) are also predicted since a substitution has produced a new start codon, although these may be mispredictions, as numerous SNPs and deletions have accumulated relative to WD0622. None of these genes include the DNA binding domains present in WD0622, suggesting that even if they are functional their activity is likely to differ significantly from that of their counterpart in $w$ Mel. Furthermore, there are IS5 elements inserted immediately downstream of the $w \mathrm{Au}$ genes corresponding to WD0622, so it may be that the regulation of the genes differs between the two strains. Genes such as this, which are conserved between multiple CI-inducing strains (WD0622 has two orthologs in the CI-inducing $w \mathrm{Ri}$ strain) but disrupted in a non-CI strain, are prime candidates for involvement in CI.

In the wMel genome, WD0254, WD0255, WD0622, WD0623 and WD0626 are in two regions that appear to be paralogous; WD0254 is a truncated paralog of WD0622 (with the truncation appearing to be due to a transposase insertion) and WD0255 a paralog of WD0623. In the wAu genome, there also appear to be two genome segments containing paralogous sequences at approximately the same genomic positions as in $w \mathrm{Mel}$. However, the segment at a similar position to WD0254 and WD0255 is inverted relative to its orientation in $w \mathrm{Mel}$ and is adjacent to genes that match WD0628-WD0630 in wMel, suggesting that one or more translocations have occurred, encompassing WD0622 to WD0630; flanking IS elements provide a putative mechanism for its translocation and inversion. Unlike in $w \mathrm{Mel}$, in which there are 
Table 2 wMel genes potentially inactive in wAu

\begin{tabular}{|c|c|c|c|}
\hline wMel gene & Function & Matching wAu gene(s) & Difference in wAu \\
\hline WD0092 & DNA processing chain $A$ & $\begin{array}{l}\text { WPWAU0139/ } \\
\text { WPWAU0140 }\end{array}$ & Frameshift \\
\hline WD0139 & Transcriptional activator, tenA family, putative & WPWAU0095 & Start codon mutation \\
\hline WD0196 & Hypothetical protein & No match & Truncation \\
\hline WD0254 & Transcriptional regulator, putative & $\begin{array}{l}\text { WPWAU0256/ } \\
\text { WPWAU0257/ } \\
\text { WPWAU0686/ } \\
\text { WPWAU0687 }\end{array}$ & Frameshift \\
\hline WD0274 & Conserved hypothetical protein & WPWAU0651 & Start codon mutation \\
\hline WD0284 & Conserved hypothetical protein & $\begin{array}{l}\text { WPWAU0640/ } \\
\text { WPWAU0641 }\end{array}$ & Frameshift \\
\hline WD0288 & $\begin{array}{l}\text { Prophage LambdaW1, site-specific } \\
\text { recombinase, resolvase family }\end{array}$ & WPWAU0636 & Nonsense mutation \\
\hline WD0294 & Ankyrin repeat domain protein & WPWAU0631 & Truncation \\
\hline WD0295 & Hypothetical protein & $\begin{array}{l}\text { WPWAU0322I } \\
\text { WPWAU0323 }\end{array}$ & Frameshift \\
\hline WD0382 & Conserved hypothetical protein & $\begin{array}{l}\text { WPWAU0417/ } \\
\text { WPWAU0418/ } \\
\text { WPWAU0419 }\end{array}$ & Frameshift \\
\hline WD0383 & Hypothetical protein & $\begin{array}{l}\text { WPWAU0420/ } \\
\text { WPWAU0421 }\end{array}$ & Frameshift \\
\hline WD0385 & Ankyrin repeat domain protein & $\begin{array}{l}\text { WPWAU0423/ } \\
\text { WPWAU0426/ } \\
\text { WPWAU0427 }\end{array}$ & Mobile element insertion \\
\hline \multirow[t]{2}{*}{ WD0446 } & Hypothetical protein & WPWAU0481/ & Frameshift \\
\hline & & WPWAU0482 & \\
\hline \multirow[t]{2}{*}{ WD0462 } & Hypothetical protein & WPWAU0494/ & Frameshift \\
\hline & & WPWAU0495 & \\
\hline WD0463 & ATPase, AAA family & WPWAU0496 & Mobile element insertion \\
\hline \multirow[t]{2}{*}{ WD0472 } & ATPase, AAA family & WPWAU0507/ & Nonsense mutation \\
\hline & & WPWAU0508 & \\
\hline WD0507 & DNA repair protein RadC, truncation & No match & Absent \\
\hline WD0508 & Transcriptional regulator, putative & No match & Absent \\
\hline WD0509 & DNA mismatch repair protein MutL-2 & No match & Absent \\
\hline WD0511 & Conserved hypothetical protein & No match & Absent \\
\hline WD0512 & Hypothetical protein & No match & Absent \\
\hline WD0513 & Hypothetical protein & No match & Absent \\
\hline WD0514 & Ankyrin repeat domain protein & No match & Absent \\
\hline WD0548 & Hypothetical protein & WPWAU0565 & Frameshift \\
\hline WD0572 & Conserved hypothetical protein & WPWAU0271 & Frameshift \\
\hline \multirow[t]{3}{*}{ WD0582 } & Regulatory protein RepA, putative & WPWAU0282I & Frameshift \\
\hline & & WPWAU0283/ & \\
\hline & & WPWAU0284 & \\
\hline WD0591 & Conserved hypothetical protein & WPWAU0289 & Frameshift \\
\hline \multirow[t]{2}{*}{ WD0594 } & Prophage LambdaW4, DNA methylase & WPWAU0291/ & Frameshift \\
\hline & & WPWAU0292 & \\
\hline \multirow[t]{2}{*}{ WD0609 } & Regulatory protein RepA, putative & WPWAU0669/ & Frameshift \\
\hline & & WPWAU0670 & \\
\hline
\end{tabular}


Table 2 wMel genes potentially inactive in wAu (Continued)

\begin{tabular}{|c|c|c|c|}
\hline \multirow[t]{2}{*}{ WD0610 } & \multirow[t]{2}{*}{ Helicase, SNF2 family } & WPWAU0671/ & \multirow[t]{2}{*}{ Nonsense mutation } \\
\hline & & WPWAU0672 & \\
\hline WD0619 & GlpT/PgpT/UhpT transporter family protein & WPWAU0681 & Frameshift \\
\hline \multirow[t]{4}{*}{ WD0622 } & \multirow[t]{4}{*}{ Transcriptional regulator, putative } & WPWAU0256/ & \multirow[t]{4}{*}{ Frameshift } \\
\hline & & WPWAU0257/ & \\
\hline & & WPWAU0686/ & \\
\hline & & WPWAU0687 & \\
\hline WD0630 & Hypothetical protein & WPWAU0249 & Truncation \\
\hline WD0631 & Hypothetical protein & No match & Absent \\
\hline WD0632 & Hypothetical protein & No match & Absent \\
\hline \multirow[t]{2}{*}{ WD0636 } & \multirow{2}{*}{$\begin{array}{l}\text { Prophage LambdaW5, ankyrin } \\
\text { repeat domain protein }\end{array}$} & WPWAU0314/ & \multirow[t]{2}{*}{ Frameshift } \\
\hline & & WPWAU0315 & \\
\hline \multirow[t]{2}{*}{ WD0638 } & \multirow[t]{2}{*}{ Conserved hypothetical protein } & WPWAU0311/ & \multirow[t]{2}{*}{ Frameshift } \\
\hline & & WPWAU0312 & \\
\hline WD0682 & Ribosomal protein S10 & WPWAU0607 & Nonsense mutation \\
\hline \multirow[t]{3}{*}{ WD0686 } & \multirow[t]{3}{*}{ Conserved domain protein } & WPWAU0613/ & \multirow[t]{3}{*}{ Mobile element insertion } \\
\hline & & WPWAU0614/ & \\
\hline & & WPWAU0618 & \\
\hline WD0696 & Hypothetical protein & WPWAU0698 & Nonsense mutation \\
\hline WD0766 & Ankyrin repeat domain protein & WPWAU0768 & Nonsense mutation \\
\hline \multirow[t]{3}{*}{ WD1041 } & \multirow[t]{3}{*}{ Surface protein-related protein } & WPWAU1092I & \multirow[t]{3}{*}{ Frameshift } \\
\hline & & WPWAU1093/ & \\
\hline & & WPWAU1094 & \\
\hline \multirow[t]{2}{*}{ WD1111 } & \multirow[t]{2}{*}{ Hypothetical protein } & WPWAU0887/ & \multirow[t]{2}{*}{ Frameshift } \\
\hline & & WPWAU0888 & \\
\hline WD1180 & Recombination protein $\operatorname{Rec} R$ & WPWAU1182 & Nonsense mutation \\
\hline WD1187 & Hypothetical protein & WPWAU1187 & Frameshift \\
\hline WD1320 & Multidrug resistance protein $\mathrm{D}$ & WPWAU1315 & Frameshift \\
\hline
\end{tabular}

Truncation refers to shortening of the gene sequence due to partial deletion or genome rearrangement. Small hypothetical genes with multiple matches are not included, as these are likely to be remnants of mobile elements. Genes annotated as truncations in wMel are not included, as these are likely to be inactive in wMel.

sequence differences between the paralogs in the two paralogous transcriptional regulator regions, in $w \mathrm{Au}$ WPWAU0687, WPWAU0686 and WPWAU0688 are identical to WPWAU0256, WPWAU0257 and WPWAU0255 respectively, while WPWAU0691 is identical to WPWAU0252 after the first $84 \mathrm{bp}$; this suggests that replacement by intragenomic recombination has occurred. WD0296 appears to have an ortholog in $w \mathrm{Au}, W P W A U 0324$, in a similar genomic position, while there is no ortholog of WD0508 present in $w \mathrm{Au}$, consistent with a previous study that found that the region spanning WD0506 to WD0518 in $w \mathrm{Mel}$ is absent from $w \mathrm{Au}$ [19]. This gene is also absent in several other CI-inducing Wolbachia strains [19].

Analysis of the other transcriptional regulator gene sequences indicates that protein products from these genes would be different between $w \mathrm{Au}$ and $w \mathrm{Mel}$ (Figure 7), particularly WD0623 and WD0626. The two identical wAu genes corresponding to WD0623 (WPWAU0255 and WPWAU0688) both have three small insertions in the putative DNA binding domains that result in an extra four amino acids and one amino acid substitution; there are 37 further amino acid substitutions, 23 of which are located in the putative DNA binding domains. There are substitutions involving proline residues; due to the unique conformational rigidity of the proline side chain, this could have a large impact on the secondary structure of any protein produced, and thus probably also its function. There are also SNPs and a 6 bp insertion in $5^{\prime}$ upstream regions where promoter elements have been shown to occur in prokaryotes, centred at -45 and -52 [37]. In the $w \mathrm{Au}$ homolog of WD0626, WPWAU0252, two small insertions in the putative DNA binding domains would result in an extra three amino acids and one amino acid substitution. In addition there are 48 amino acid substitutions, 27 of which 


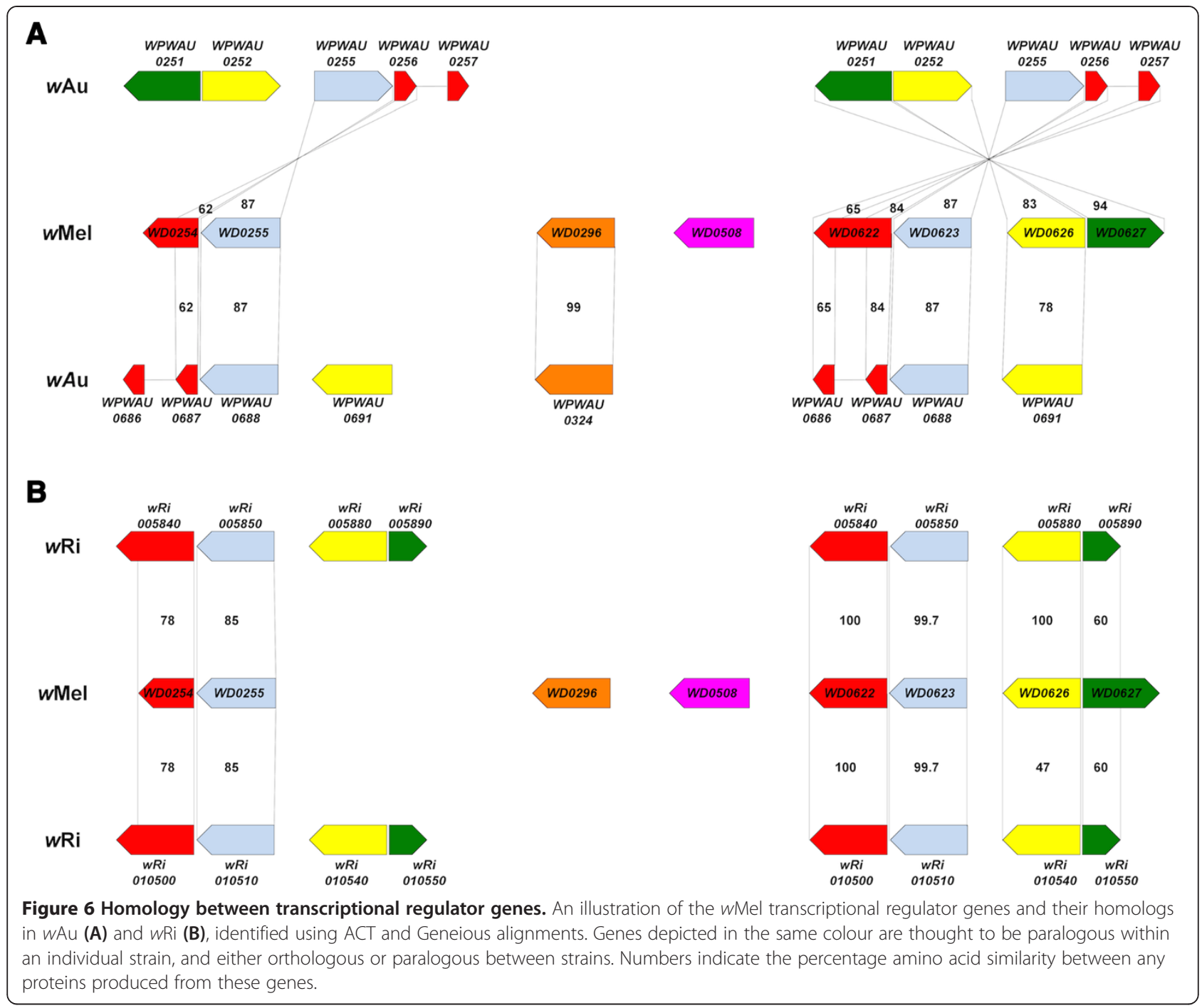

are located in the putative DNA binding domains. There are also SNPs and a 16 bp deletion in the $5^{\prime}$ upstream region spanning the -45 and -52 positions. Another factor that may affect expression is their different genomic location; in wMel, WD0622, WD0623 and WD0626 are located within a prophage region, whereas in $w A u$ this is not the case. The precise impact of all these differences described on protein function is hard to predict, but given in particular the changes in DNA binding domains it seems highly likely that their activity will be affected.

The total SNP density and the density of nonsynonymous SNPs (dN) for WD0623 and WD0626 relative to their $w \mathrm{Au}$ orthologs are at the extreme end of the distributions of these measures over the genome (Figure 8). Comparing these measures between gene categories shows that the transcriptional regulator genes as a whole have a much higher density of total SNPs and non-synonymous SNPs than all other categories, as well as a higher density of synonymous SNPs (dS) (Figure 9). A Kruskal-Wallis test shows a statistically significant difference between groups for total SNP density, $\mathrm{dN}$ and $\mathrm{dS}(\mathrm{P}<0.01$ in all cases), and post-hoc pairwise Wilcoxon tests with Benjamini-Hochberg correction show a statistically significant difference in total SNP density and dN between the transcriptional regulator genes and all other categories except genes for ankyrin repeat proteins $(\mathrm{P}<0.05$ in all cases). dS was not significantly different between transcriptional regulator genes and other groups, except the structural protein and hypothetical protein groups. These findings suggest that the transcriptional regulator genes may be under positive selection.

To confirm whether any of these transcriptional regulator genes are involved in $\mathrm{CI}$, functional studies are required, although these are currently difficult to undertake in the absence of an effective Wolbachia transformation methodology. Expression vectors have been used for transfection and shown to change transcription levels of a host cell cycle regulator, but their tissue distribution is 


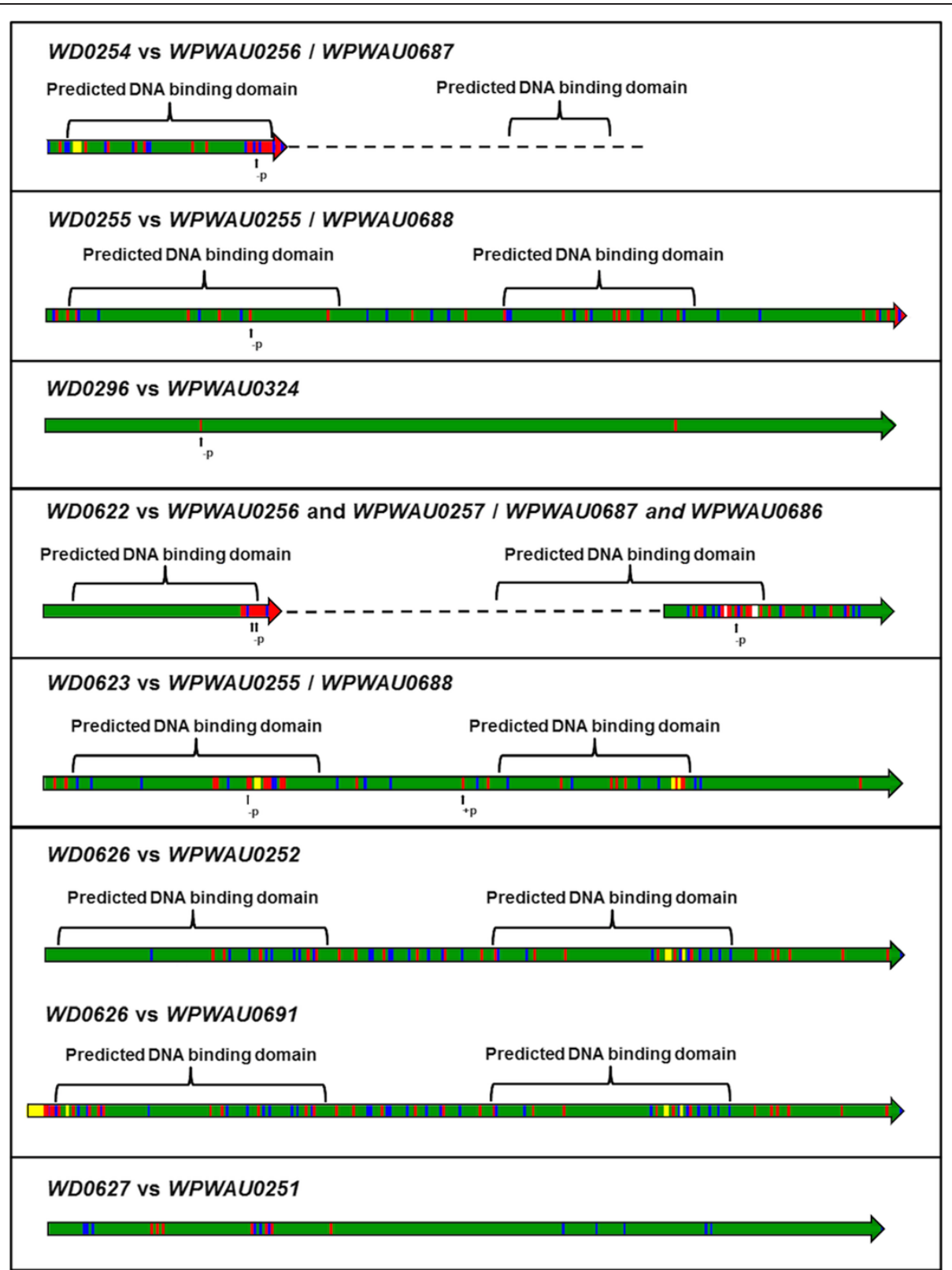

Figure 7 Differences in proteins from transcriptional regulator genes between wAu and wMel. An illustration of the differences between proteins that would be produced from the wMel transcriptional regulator genes and their corresponding sequences in wAu. Proteins predicted from the wAu sequences are shown. Green indicates identity with the wMel translated sequence. Blue indicates substitution with a similar amino acid. Red indicates substitution with a dissimilar amino acid. Yellow indicates inserted amino acids that are present in the wAu protein but not the wMel protein. White indicates deleted amino acids that are present in the wMel protein but not the wAu protein. The locations of DNA binding domains predicted from the translated wMel sequences are shown. Substitutions involving proline residues are indicated with arrows. - p: loss of a proline residue; + p: gain of a proline residue.

uneven, limiting their use for examining whether a CI-like phenotype can be induced [22]. The best approach may be to transform hosts with target Wolbachia genes and assess whether a CI phenotype can be induced, as has been performed for ankyrin repeat-encoding genes previously [38], although if multiple interacting Wolbachia genes are required to produce the CI phenotype the use of individual genes in this way may not clearly reveal their role. As more Wolbachia genomes are sequenced, further comparison of these genes between different strains will also be useful.

\section{Conclusions}

In this study, a methodology for conveniently extracting Wolbachia gDNA for genome sequencing using an 


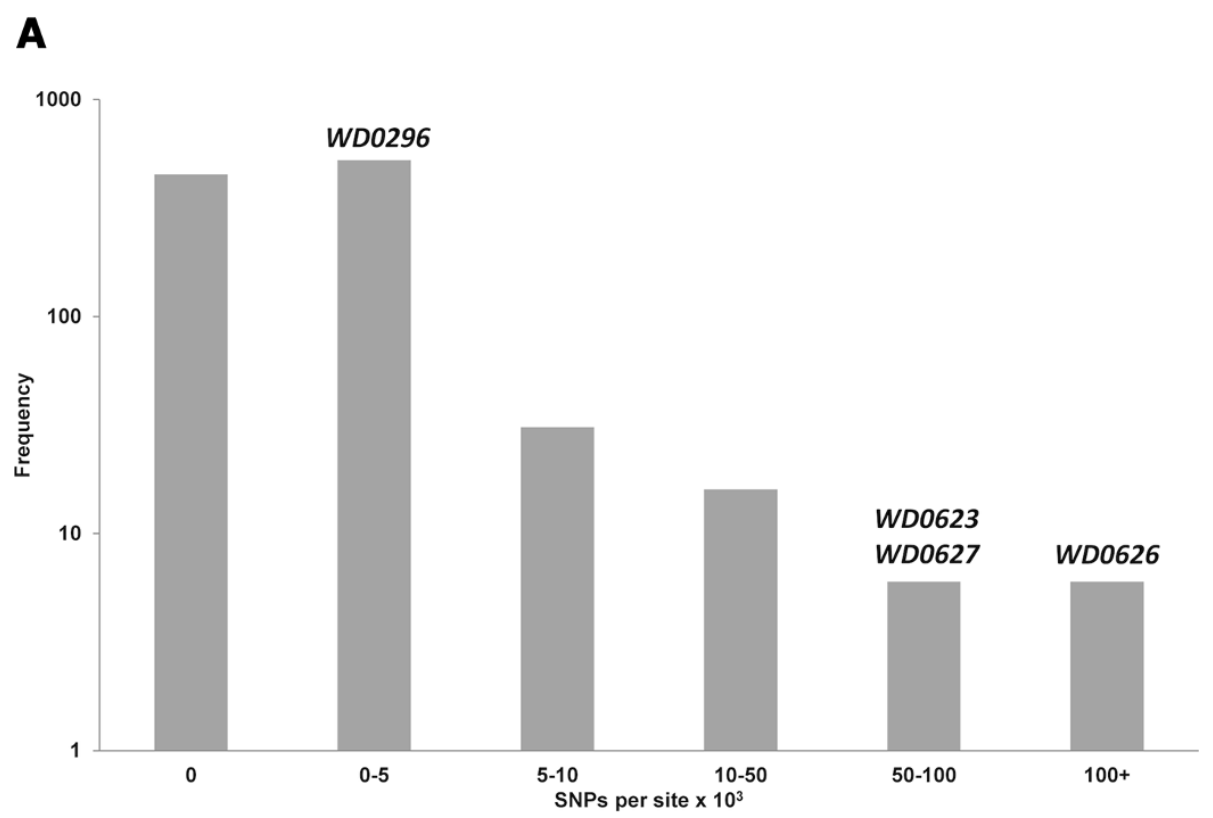

B

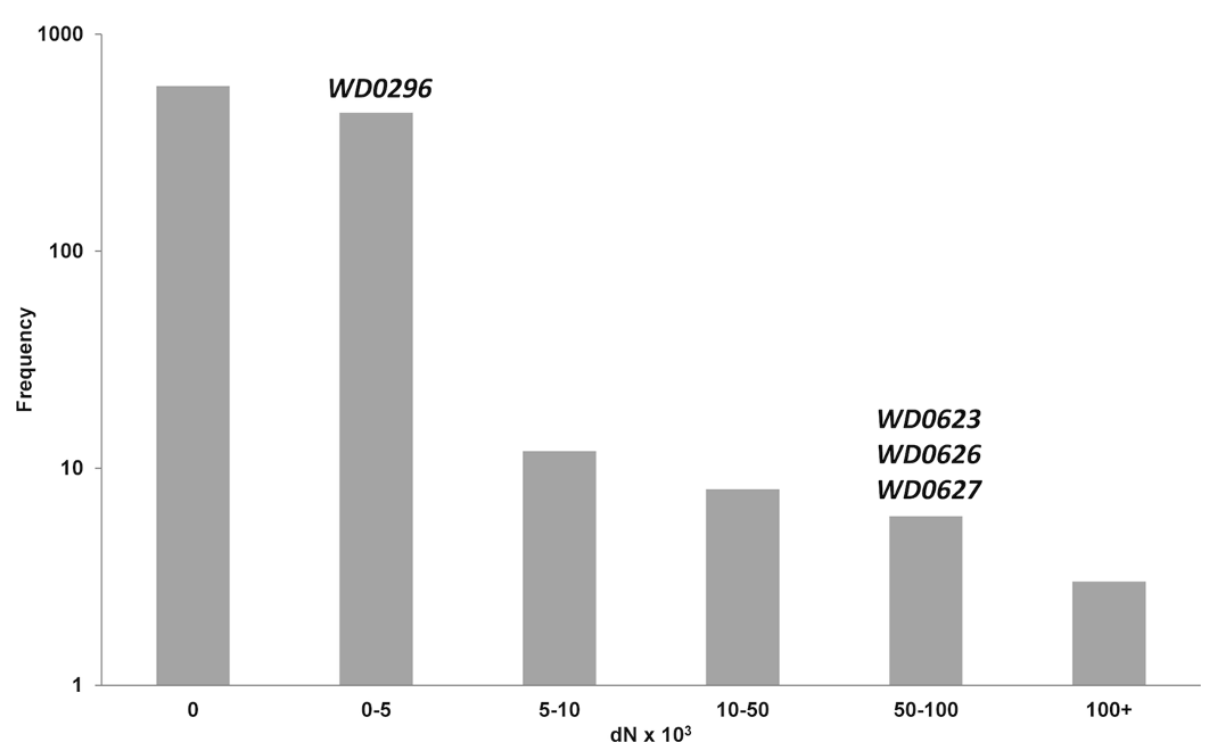

Figure 8 Frequency distribution of SNP density and $\mathbf{d N}$. Graph showing the number of protein-coding genes in the wMel genome within each SNP density $(\mathbf{A})$ and $d N(B)$ category. The frequency axis is drawn on a log scale. The bins containing the transcriptional regulator genes included in the analysis are indicated. Pseudogenes, genes that are potentially inactivated in WAu, IS elements and other genes with multiple ambiguous matches are excluded. The transcriptional regulator gene WD0255 is excluded as its closest wAu sequence contains a frameshift and is more similar to WD0623. $\mathrm{dN}$ - number of non-synonymous SNPs per potential site.

infected cell line has been successfully employed, and the PacBio RS II sequencing platform has proved a very useful tool for achieving a complete bacterial assembly, particularly when combined with Illumina sequencing. Using this approach, a single contig assembly has been generated for the genome of the $w \mathrm{Au}$ strain, which does not induce CI. Comparison of this genome to that of $w \mathrm{Mel}$, which does induce CI, revealed significant structural differences in the prophage regions and loss or potential inactivation of a number of genes. Transcriptional regulator genes in particular displayed considerable differences between $w \mathrm{Au}$ and $w \mathrm{Mel}$, both in terms of genomic location and sequence; of these the $w$ Mel gene WD0622 may be the most promising to examine as a CI candidate. Given that a 


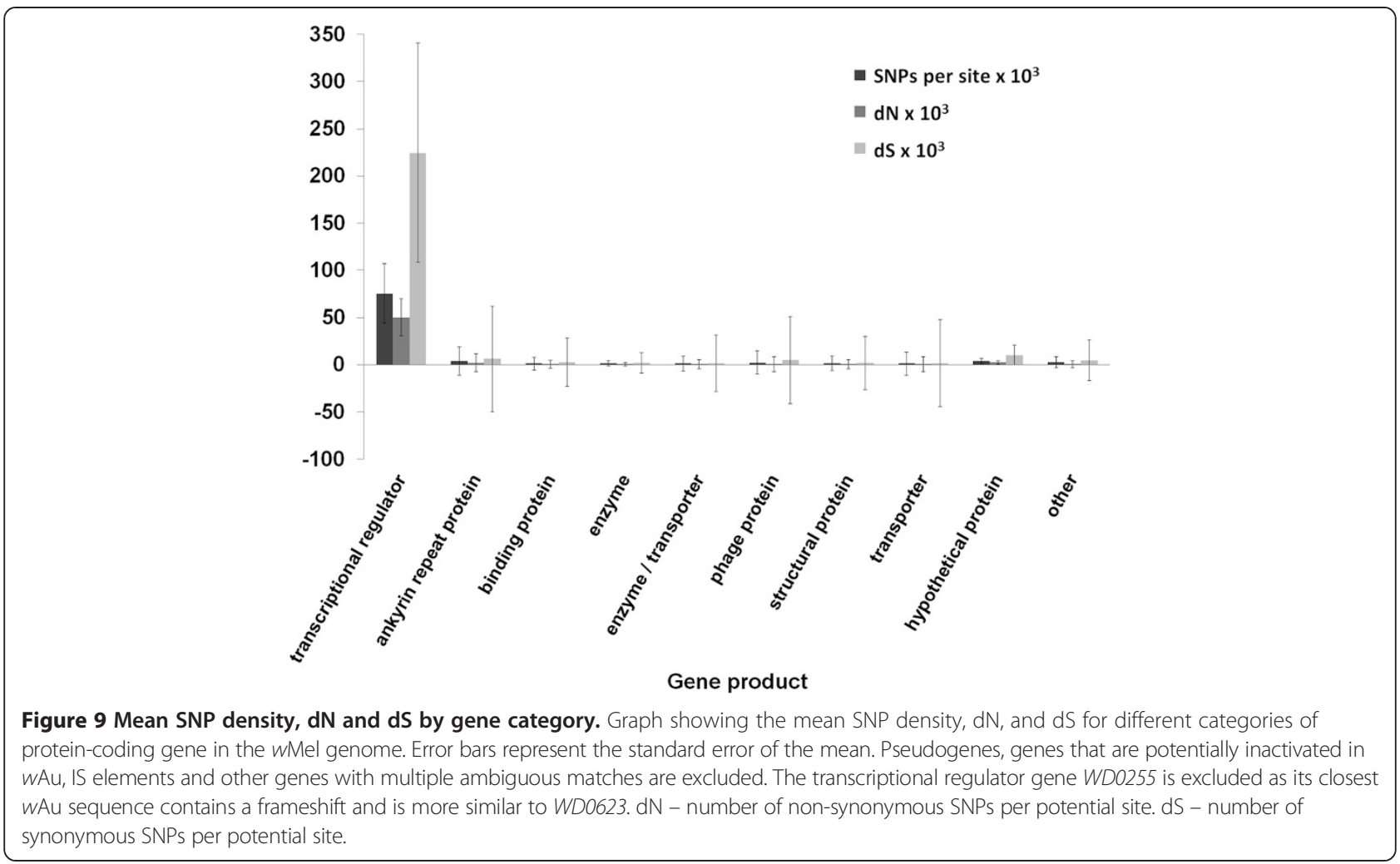

transcriptional regulator gene has previously been implicated in CI, these represent important targets for further functional studies on the mechanism of CI. The $w$ Mel genome region containing the transcriptional regulator genes WD0622, WD0633, WD0626 and WD0627 is also of particular interest with respect to $\mathrm{CI}$ given the proximity of WD0631-2, absent in $w \mathrm{Au}$, because a WD0631 ortholog protein was recently identified in mosquito spermathecae. The current study thus contributes to the important basic aim of gaining a better understanding of the molecular basis of $\mathrm{CI}$.

\section{Methods}

\section{Drosophila rearing}

D. simulans flies infected with $w \mathrm{Au}$ from Coffs Harbour, Australia, were reared using standard techniques. Flies were maintained at $25^{\circ} \mathrm{C}$ with a $12: 12$ hour light: dark cycle, in plastic bottles containing $25 \mathrm{ml}$ food, and transferred to fresh containers when necessary.

\section{Cell culture}

Aedes albopictus A $\alpha 23$ cells infected with wAu were maintained using standard cell culture techniques. Cells were maintained in an incubator at $28^{\circ} \mathrm{C}$, in flasks containing $10 \mathrm{ml}$ Schneider's medium with $10 \%$ fetal bovine serum, penicillin and streptomycin, and passaged when required.

\section{Genomic DNA extraction}

gDNA for genome sequencing was extracted using two different methods. To extract gDNA from whole flies, a slightly modified version of the protocol used by IturbeOrmaetxe et al. [27] was used. Approximately 10-25 ml flies were collected, sterilised in $50 \%$ bleach for 3 minutes, rinsed in filter-sterilised $\mathrm{dH}_{2} \mathrm{O}$, then further sterilised in $70 \%$ ethanol and rinsed again in filter-sterilised $\mathrm{dH}_{2} \mathrm{O}$. The flies were then homogenised in cold SPG buffer (3.8 $\mathrm{mM} \mathrm{KH}_{2} \mathrm{PO}_{4}, 4.9 \mathrm{mM}$ L-glutamate, $7.2 \mathrm{mM} \mathrm{K}_{2} \mathrm{HPO}_{4}$, and $218 \mathrm{mM}$ sucrose) using a Polytron homogeniser (Kinematica, Switzerland). After homogenisation the sample was centrifuged at $3,200 \mathrm{~g}$ for 15 minutes. The supernatant was collected and the centrifugation repeated. The supernatant from the second centrifugation was sequentially filtered through $5 \mu \mathrm{m}, 2.7 \mu \mathrm{m}$ and $1.2 \mu \mathrm{m}$ syringe filters. The filtrate was centrifuged at $18,000 \mathrm{~g}$ for 20 minutes to pellet Wolbachia, which were resuspended in cold SPG buffer. The suspension was then incubated with $600 \mathrm{ng}$ of DNase I (Roche, UK) at $37^{\circ} \mathrm{C}$ for 30 minutes and subsequently with $5 \mu \mathrm{l}$ of RNase A (Fermentas, UK) at $37^{\circ} \mathrm{C}$ for 15 minutes to remove host DNA and RNA contamination. Cells were 
then lysed by incubation with $200 \mu \mathrm{g}$ of proteinase $\mathrm{K}$ (Sigma-Aldrich, UK) at $56^{\circ} \mathrm{C}$. gDNA was purified using two phenol/chloroform/isoamyl alcohol extractions and one chloroform/isoamyl alcohol extraction.

To extract gDNA from cells, Wolbachia were first purified from the cells. Cells were dislodged from flasks by pipetting and scraping, and lysed by vortexing with borosilicate beads. The lysate was centrifuged at 2,500 $\mathrm{g}$ for 10 minutes at $4^{\circ} \mathrm{C}$, then filtered sequentially through $5 \mu \mathrm{m}$ and $0.2 \mu \mathrm{m}$ filters. Sucrose gradient centrifugation was performed at $18.500 \mathrm{~g}$ for $10-20$ minutes at $4^{\circ} \mathrm{C}$ to pellet the Wolbachia. gDNA was purified using the method described by Livak [39]. To extract gDNA for PCR, the Livak method was used on adult $w \mathrm{Au}$-infected flies.

\section{Genomic DNA purity assessment}

Extracted $w A$ un gDA was analysed for contamination with host gDNA using qPCR. Reactions were performed on five serial dilutions of the extracts, using primers specific for a $w A$ u gene (wsp), a host nuclear gene (RpL32 for D. simulans and hth for Ae. albopictus) and a host mitochondrial sequence (mitochondrial rRNA). The average relative $C(t)$ values for each primer pair, corrected for differences in primer efficiencies, were calculated. Taking into account the different sizes of the genomes, these values were compared to give a ratio of the amount of $w \mathrm{Au}$ gDNA to host gDNA, and the figures in this ratio were converted into percentages.

\section{Genome sequencing and assembly}

$w \mathrm{Au}$ gDNA extracted from whole files was sequenced using the Illumina HiSeq 2000 platform. A 200300 bp paired end library was constructed following the methods described by Quail et al. [40,41], using Kapa HiFi polymerase for PCR to reduce GC bias [42]. The library was given a unique index and sequenced as part of a lane with other samples. $357 \mathrm{Mb}$ of data was generated from 3,565,172 reads of $100 \mathrm{bp}$. An assembly was generated from these reads with Velvet [43], using the $w$ Mel genome as a reference. The final assembly comprised 77 contigs, with a total length of 1,222,634 bp, an N50 of $29.5 \mathrm{~kb}$ and a mean coverage of $283 \times$.

$w \mathrm{Au}$ gDNA extracted from cells was sequenced using the PacBio RS II platform. A $\sim 10 \mathrm{kbp}$ library was constructed following standard protocols using a PacBio DNA Template Prep Kit. Three SMRT ${ }^{\bullet}$ cells from this library were sequenced, with a movie length of 2 hours. With filters set to exclude reads of quality $<0.8$, polymerase read length $<500 \mathrm{bp}$ and sub-read length $<500 \mathrm{bp}$, $139 \mathrm{Mb}$ of data was generated from 75,456 sub-reads (from 39,514 polymerase reads), with a mean sub-read length of 1,847 bp. A de novo assembly was generated from these sub-reads using the Hierarchical Genome Assembly Process (HGAP) version 1.0 [44], with the genome size parameter set to $1.2 \mathrm{Mb}$. This resulted in an assembly comprising a single contig of $1,273,534 \mathrm{bp}$, with a mean coverage of $62 \times$.

Errors in the assembly were corrected using the data from the Illumina sequencing. The Illumina reads from the second sample were mapped to the assembly using SMALT [45], then the assembly sequence was modified based on the mapped reads using Iterative Correction of Reference Nucleotides (iCORN) [46] with four iterations, resulting in the correction of 1 SNP and 88 indels.

\section{Genome annotation}

The assembly was annotated using the Automated Annotation Pipeline at the Wellcome Trust Sanger Institute, with the software Prokka [47]. Infernal [48] was used to identify RNA structures, followed by ARAGORN [49], Rnammer [50] and Prodigal [51] to identify transfer RNAs (tRNAs) and transfer messenger RNAs (tmRNAs), ribosomal RNAs (rRNAs) and proteins, respectively. The predicted genes were compared against Wolbachia sequences from RefSeq [52], using CD-hit [53] to create a nonredundant protein database, then against UniProtKB/SwissProt [54]. Some annotations were edited manually.

\section{Comparative analysis}

The $w \mathrm{Mel}$ and $w \mathrm{Au}$ genomes were compared using Artemis Comparison Tool (ACT) [55]. Sequences of individual genes of interest were extracted and alignments and translations generated using Geneious 7.0.5, created by Biomatters [56]. Predicted protein domains were identified using InterPro [57]. SNP analysis was performed with the aid of Synonymous Non-synonymous Analysis Program (SNAP) v1.1.1 [58,59]. The Gene Ontology (GO) project [60] was used to aid categorisation of genes. The dot plot comparing $w \mathrm{Au}$ and $w \mathrm{Mel}$ genomes was generated using Dotter [61] with default parameters.

\section{Sequence confirmation}

The sequences of regions of interest were confirmed using PCR. Primers were designed to flank the regions of interest in the $w \mathrm{Au}$ genome. Amplification was performed using standard PCR conditions. PCR products were run on an agarose gel to check their size, then purified using a Qiagen PCR purification kit and sequenced using GATC Biotech sequencing.

\section{Availability of supporting data}

The $w \mathrm{Au}$ genome sequence has been submitted to the EMBL/GenBank/DDBJ database with the accession number LK055284. The raw Illumina sequence reads have been submitted to the European Nucleotide Archive with the accession number ERS151014. 


\section{Abbreviations}

ACT: Artemis comparison tool; bp: Base pair; CDS: Coding sequence; Cl: Cytoplasmic incompatibility; Cx: Culex; D: Drosophila; gDNA: genomic DNA; HGAP: Hierarchical Genome Assembly Process; iCORN: Iterative Correction of Reference Nucleotides; IS: Insertion sequence; qPCR: Quantitative polymerase chain reaction; PCR: Polymerase chain reaction; rRNA: Ribosomal RNA; SEM: Standard error of the mean; SNAP: Synonymous Non-synonymous Analysis Program; SNP: Single nucleotide polymorphism; tRNA: Transfer RNA; tmRNA: Transfer messenger RNA.

\section{Competing interests}

The authors declare that they have no competing interests.

\section{Authors' contributions}

Initial design and co-ordination of study: SPS, ERS, JP. Laboratory work: ERS. Data analysis: ERS, SRH. Manuscript drafting: ERS, SPS. All authors read and approved the final manuscript.

\section{Acknowledgements}

We thank the Wellcome Trust Sanger Institute core sequencing and informatics groups for library preparation and sequencing using the Illumina platform, and P. Coupland for his contribution to library preparation and sequencing using the PacBio platform. We thank S. Pinto for providing wAu-infected cells, K. Clarke for use of equipment and M. Blagrove for input on the manuscript. This work was supported by grants WT095121MA and WT098051 from the Wellcome Trust and grant BB/J012696/1 from the BBSRC.

\section{Author details}

${ }^{1}$ Department of Zoology and Peter Medawar Building for Pathogen Research, Nuffield Department of Medicine, University of Oxford, Oxford, UK ${ }^{2}$ Pathogen Genomics, Wellcome Trust Sanger Institute, Wellcome Trust Genome Campus, Hinxton, Cambridge, UK. ${ }^{3}$ Biomedical and Life Sciences, Lancaster University, Lancaster, UK.

\section{Received: 22 April 2014 Accepted: 15 October 2014}

Published: 24 October 2014

\section{References}

1. Zug R, Hammerstein P: Still a host of hosts for Wolbachia: analysis of recent data suggests that $40 \%$ of terrestrial arthropod species are infected. PLoS One 2012, 7:e38544.

2. Werren JH, Baldo L, Clark ME: Wolbachia: master manipulators of invertebrate biology. Nat Rev Microbiol 2008, 6:741-751.

3. Moreira LA, Iturbe-Ormaetxe I, Jeffery JA, Lu G, Pyke AT, Hedges LM, Rocha BC, Hall-Mendelin S, Day A, Riegler M, Hugo LE, Johnson KN, Kay BH, McGraw EA, van den Hurk AF, Ryan PA, O'Neill SL: A Wolbachia symbiont in Aedes aegypti limits infection with dengue, chikungunya, and Plasmodium. Cell 2009, 139:1268-1278.

4. Bian G, Xu Y, Lu P, Xie Y, Xi Z: The endosymbiotic bacterium Wolbachia induces resistance to dengue virus in Aedes aegypti. PLoS Pathog 2010, 6:e1000833

5. Walker $\mathrm{T}$, Johnson PH, Moreira LA, Iturbe-Ormaetxe I, Frentiu FD, McMeniman $\mathrm{CJ}$, Leong YS, Dong Y, Axford J, Kriesner P, Lloyd AL, Ritchie SL, O'Neill SL, Hoffmann AA: The wMel Wolbachia strain blocks dengue and invades caged Aedes aegypti populations. Nature 2011, 476:450-453.

6. Blagrove MS, Arias-Goeta C, Failloux AB, Sinkins SP: Wolbachia strain wMel induces cytoplasmic incompatibility and blocks dengue transmission in Aedes albopictus. Proc Natl Acad Sci U S A 2012, 109:255-260.

7. Blagrove MS, Arias-Goeta C, Di Genua C, Failloux AB, Sinkins SP: A Wolbachia wMel transinfection in Aedes albopictus is not detrimental to host fitness and inhibits chikungunya virus. PLOS Negl Trop Dis 2013, 7:e2152.

8. Kambris Z, Cook PE, Phuc HK, Sinkins SP: Immune activation by life-shortening Wolbachia and reduced filarial competence in mosquitoes. Science 2009 326:134-136.

9. Kambris Z, Blagborough AM, Pinto SB, Blagrove MS, Godfray HC, Sinden RE, Sinkins SP: Wolbachia stimulates immune gene expression and inhibits plasmodium development in Anopheles gambiae. PLoS Pathog 2010, 6:e1001143.

10. Hughes GL, Koga R, Xue P, Fukatsu T, Rasgon JL: Wolbachia infections are virulent and inhibit the human malaria parasite Plasmodium falciparum in Anopheles gambiae. PLoS Pathog 2011, 7:e1002043.
11. Bian G, Joshi D, Dong Y, Lu P, Zhou G, Pan X, Xu Y, Dimopoulos G, Xi Z: Wolbachia invades Anopheles stephensi populations and induces refractoriness to Plasmodium infection. Science 2013, 340:748-751.

12. Hoffmann AA, Montgomery BL, Popovici J, Iturbe-Ormaetxe I, Johnson PH, Muzzi F, Greenfield M, Durkan M, Leong YS, Dong Y, Cook H, Axford J, Callahan AG, Kenny N, Omodei C, McGraw EA, Ryan PA, Ritchie SA, Turelli M, O'Neill SL: Successful establishment of Wolbachia in Aedes populations to suppress dengue transmission. Nature 2011, 476:454-457.

13. Hoffmann AA, Clancy D, Duncan J: Naturally-occurring Wolbachia infection in Drosophila simulans that does not cause cytoplasmic incompatibility. Heredity 1996, 76:1-8.

14. James AC, Ballard JW: Expression of cytoplasmic incompatibility in Drosophila simulans and its impact on infection frequencies and distribution of Wolbachia pipientis. Evolution 2000, 54:1661-1672.

15. Reynolds KT, Hoffmann AA: Male age, host effects and the weak expression or non-expression of cytoplasmic incompatibility in Drosophila strains infected by maternally transmitted Wolbachia. Genet Res 2002, 80:79-87

16. Charlat S, Le Chat L, Merçot H: Characterization of non-cytoplasmic incompatibility inducing Wolbachia in two continental African populations of Drosophila simulans. Heredity 2003, 90:49-55.

17. Kriesner P, Hoffmann A, Lee SF, Turelli M, Weeks AR: Rapid sequential spread of two Wolbachia variants in Drosophila simulans. PLOS Pathog 2013, 9:e1003607.

18. Osborne SE, Leong YS, O'Neill SL, Johnson KN: Variation in antivira protection mediated by different Wolbachia strains in Drosophila simulans. PLoS Pathog 2009, 5:e1000656.

19. Iturbe-Ormaetxe I, Burke GR, Riegler M, O'Neill SL: Distribution, expression, and motif variability of ankyrin domain genes in Wolbachia pipientis. J Bacteriol 2005, 187:5136-5145.

20. Wu M, Sun LV, Vamathevan J, Riegler M, Deboy R, Brownlie JC, McGraw EA Martin W, Esser C, Ahmadinejad N, Wiegand C, Madupu R, Beanan MJ, Brinkac LM, Daugherty SC, Durkin AS, Kolonay JF, Nelson WC, Mohamoud Y, Lee P, Berry K, Young MB, Utterback T, Weidman J, Nierman WC, Paulsen IT, Nelson KE, Tettelin H, O'Neill SL, Eisen JA: Phylogenomics of the reproductive parasite Wolbachia pipientis wMel: a streamlined genome overrun by mobile genetic elements. PLoS Biol 2004, 2:E69.

21. Klasson L, Walker T, Sebaihia M, Sanders MJ, Quail MA, Lord A, Sanders S, Earl J, O'Neill SL, Thomson N, Sinkins SP, Parkhill J: Genome evolution of Wolbachia strain wPip from the Culex pipiens group. Mol Biol Evol 2008 25:1877-1887.

22. Pinto SB, Stainton K, Harris S, Kambris Z, Sutton ER, Bonsall MB, Parkhill J, Sinkins SP: Transcriptional Regulation of Culex pipiens mosquitoes by Wolbachia influences cytoplasmic incompatibility. PLOS Pathog 2013, 9:e1003647.

23. Foster J, Ganatra M, Kamal I, Ware J, Makarova K, Ivanova N, Bhattacharyya A, Kapatral V, Kumar S, Posfai J, Vincze T, Ingram J, Moran L, Lapidus A, Omelchenko M, Kyrpides N, Ghedin E, Wang S, Goltsman E, Joukov V, Ostrovskaya O, Tsukerman K, Mazur M, Comb D, Koonin E, Slatko B: The Wolbachia genome of Brugia malayi: endosymbiont evolution within a human pathogenic nematode. PLOS Biol 2005, 3:e121.

24. Klasson L, Westberg J, Sapountzis P, Naslund K, Lutnaes Y, Darby AC, Veneti Z, Chen L, Braig HR, Garrett R, Bourtzis K, Andersson SG: The mosaic genome structure of the Wolbachia wRi strain infecting Drosophila simulans. Proc Natl Acad Sci U S A 2009, 106:5725-5730.

25. Mavingui P, Valiente Moro C, Tran-Van V, Wisniewski-Dye F, Raquin V, Minard G, Tran FH, Voronin D, Rouy Z, Bustos P, Lozano L, Barbe V, González V: WholeGenome Sequence of Wolbachia Strain wAlbB, an Endosymbiont of Tiger Mosquito Vector Aedes albopictus. J Bacteriol 2012, 194:1840

26. Ellegaard KM, Klasson L, Näslund K, Bourtzis K, Andersson SG: Comparative genomics of Wolbachia and the bacterial species concept. PLoS Genet 2013, 9:e1003381.

27. Iturbe-Ormaetxe I, Woolfit M, Rancès E, Duplouy A, O'Neill SL: A simple protocol to obtain highly pure Wolbachia endosymbiont DNA for genome sequencing. J Microbiol Methods 2011, 84:134-136.

28. Quail MA, Smith M, Coupland P, Otto TD, Harris SR, Connor TR, Bertoni A, Swerdlow HP, GU Y: A tale of three next generation sequencing platforms: comparison of Ion Torrent, Pacific Biosciences and Illumina MiSeq sequencers. BMC Genomics 2012, 13:341.

29. Au KF, Underwood JG, Lee L, Wong WH: Improving PacBio long read accuracy by short read alignment. PLoS One 2012, 7:e46679. 
30. Koren S, Schatz MC, Walenz BP, Martin J, Howard JT, Ganapathy G, Wang Z, Rasko DA, McCombie WR, Jarvis ED, Phillippy AM: Hybrid error correction and de novo assembly of single-molecule sequencing reads. Nat Biotechnol 2012, 30:693-700.

31. Ribeiro FJ, Przybylski D, Yin S, Sharpe T, Gnerre S, Abouelleil A, Berlin AM Montmayeur A, Shea TP, Walker BJ, Young SK, Russ C, Nusbaum C, MacCallum I, Jaffe DB: Finished bacterial genomes from shotgun sequence data. Genome Res 2012, 22(11):2270-2277.

32. Masui $S$, Kuroiwa $H$, Sasaki T, Inui M, Kuroiwa T, Ishikawa H: Bacteriophage WO and virus-like particles in Wolbachia, an endosymbiont of arthropods. Biochem Biophys Res Commun 2001, 283:1099-1104.

33. McGraw EA, Merritt DJ, Droller JN, O'Neill SL: Wolbachia-mediated sperm modification is dependent on the host genotype in Drosophila. Proc Biol Sci 2001, 268(1485):2565-2570.

34. Sinkins SP, Walker T, Lynd A, Steven A, Makepeace B, Godfray HCJ, Parkhill J: Wolbachia variability and host effects on crossing type in Culex mosquitoes. Nature 2005, 436(7048):257-260.

35. Zabalou S, Apostolaki A, Pattas S, Veneti Z, Paraskevopoulos C, Livadaras I, Markakis G, Brissac T, Merçot H, Bourtzis K: Multiple rescue factors within a Wolbachia strain. Genetics 2008, 178(4):2145-2160.

36. Beckmann JF, Fallon AM: Detection of the Wolbachia Protein WPIP0282 in Mosquito Spermathecae: Implications for Cytoplasmic Incompatibility. Insect Biochem Mol Biol 2013, 43(9):867-878.

37. Ross W, Gosink KK, Salomon J, Igarashi K, Zou C, Ishihama A, Severinov K, Gourse RL: A third recognition element in bacterial promoters: DNA binding by the alpha subunit of RNA polymerase. Science 1993, 262:1407-1413.

38. Yamada R, Iturbe-Ormaetxe I, Brownlie JC, O'Neill SL: Functional test of the influence of Wolbachia genes on cytoplasmic incompatibility expression in Drosophila melanogaster. Insect Mol Biol 2011, 20:75-85.

39. Livak KJ: Organization and mapping of a sequence on the Drosophila melanogaster $X$ and $Y$ chromosomes that is transcribed during spermatogenesis. Genetics 1984, 107:611-634.

40. Quail MA, Kozarewa I, Smith F, Scally A, Stephens PJ, Durbin R, Swerdlow H, Turner DJ: A large genome center's improvements to the Illumina sequencing system. Nat Methods 2008, 5:1005-1010.

41. Quail MA, Swerdlow H, Turner DJ: Improved protocols for the illumina genome analyzer sequencing system. Curr Protoc Hum Genet 2009 Chapter 18(Unit 18):12.

42. Quail MA, Otto TD, Gu Y, Harris SR, Skelly TF, McQuillan JA, Swerdlow HP Oyola SO: Optimal enzymes for amplifying sequencing libraries. Nat Methods 2012, 9:10-11.

43. Zerbino DR, Birney E: Velvet: algorithms for de novo short read assembly using de Bruijn graphs. Genome Res 2008, 18(5):821-829.

44. Chin CS, Alexander DH, Marks P, Klammer AA, Drake J, Heiner C, Clum A Copeland A, Huddleston J, Eichler EE, Turner SW, Korlach J: Nonhybrid, finished microbial genome assemblies from long-read SMRT sequencing data. Nat Methods 2013, 10:563-569.

45. SMALT [http://www.sanger.ac.uk/resources/software/smalt/]

46. Otto TD, Sanders M, Berriman M, Newbold C: Iterative Correction of Reference Nucleotides (iCORN) using second generation sequencing technology. Bioinformatics 2013, 26(14):1704-7.

47. Prokka: Prokaryotic Genome Annotation System [http://vicbioinformatics.com/]

48. Nawrocki EP, Eddy SR: Infernal 1.1: 100-fold faster RNA homology searches. Bioinformatics 2013, 29:2933-2935.

49. Laslett $D$, Canback B: ARAGORN, a program to detect tRNA genes and tmRNA genes in nucleotide sequences. Nucleic Acids Res 2004, 32:11-16.

50. Lagesen $\mathrm{K}$, Hallin P, Rødland EA, Stærfeldt HH, Rognes T, Ussery DW: RNammer: consistent annotation of rRNA genes in genomic sequences. Nucleic Acids Res 2007, 35(9):3100-3108.

51. Hyatt D, Chen GL, Locascio PF, Land ML, Larimer FW, Hauser L: Prodigal: prokaryotic gene recognition and translation initiation site identification. BMC Bioinformatics 2010, 11:119.

52. Pruitt KD, Tatusova T, Klimke W, Maglott DR: NCBI Reference Sequences: current status, policy and new initiatives. Nucleic Acids Res 2009, 37:D32-36.

53. Fu L, Niu B, Zhu Z, Wu S, Li W: CD-HIT: accelerated for clustering the next-generation sequencing data. Bioinformatics 2012, 28:3150-3152.

54. Consortium U: Update on activities at the Universal Protein Resource (UniProt) in 2013. Nucleic Acids Res 2013, 41:D43-47.

55. Carver TJ, Rutherford KM, Berriman M, Rajandream MA, Barrell BG, Parkhill J: ACT: the Artemis Comparison Tool. Bioinformatics 2005, 21:3422-3423.
56. Geneious version 7.0.5 created by Biomatters [http://www.geneious.com]

57. Hunter S, Jones P, Mitchell A, Apweiler R, Attwood TK, Bateman A, Bernard T, Binns D, Bork P, Burge S, de Castro E, Coggill P, Corbett M, Das U, Daugherty L, Duquenne L, Finn RD, Fraser M, Gough J, Haft D, Hulo N, Kahn D, Kelly E, Letunic I, Lonsdale D, Lopez R, Madera M, Maslen J, McAnulla C, McDowall J, et al: InterPro in 2011: new developments in the family and domain prediction database. Nucleic Acids Res 2012, 40:D306-312.

58. SNAP V1.1.1; [www.hiv.lanl.gov]

59. Korber B: HIV Signature and Sequence Variation Analysis. In Computational Analysis of HIV Molecular Sequences. Edited by Rodrigo AG Learn GH. Dordrecht, Netherlands: Kluwer Academic Publishers; 2000:55-72.

60. The Gene Ontology Consortium: Gene ontology: tool for the unification of biology. Nat Genet 2000, 25(1):25-9.

61. Sonhammer ELL, Durbin R: A dot-matrix program with dynamic threshold control suited for genomic DNA and protein sequence analysis. Gene 1995, 167:GC1-10.

doi:10.1186/1471-2164-15-928

Cite this article as: Sutton et al:: Comparative genome analysis of Wolbachia strain wAu. BMC Genomics 2014 15:928.

\section{Submit your next manuscript to BioMed Central and take full advantage of:}

- Convenient online submission

- Thorough peer review

- No space constraints or color figure charges

- Immediate publication on acceptance

- Inclusion in PubMed, CAS, Scopus and Google Scholar

- Research which is freely available for redistribution

Submit your manuscript at www.biomedcentral.com/submit
C BioMed Central 